\title{
The Role of Language in Intercultural Communication
}

Tatiana Seregina, ${ }^{+*}$ Svetlana Zubanova, ${ }^{\ddagger}$ Viktor Druzhinin, ${ }^{\prime}$ and Guzalia Shagivaleeva ${ }^{\uparrow}$

\section{Abstract}

Intercultural dialogue as a critical component of modern society should contribute to the selfidentification of a person in the cultural space. This research aims to demonstrate the importance of multiculturalism - learning a second language in the Russian system of higher education. To accomplish the research objectives, 78 students were recruited at Tula State University, 158 students at Kuban State University and 152 technical students at Moscow Aviation Institute. Analysing and comparing experiments on learning a second language, the findings determine the effective methods and forms of teaching. In doing so, the research foregrounds some forms of effective teaching and indicates the ways to achieve them. In other words, the findings made it possible to identify the effective strategies for teaching a foreign language both in local and global level.

Keywords: Globalisation; Intercultural Communication; Multicultural Dialogue; Intercultural Education Universal

\footnotetext{
${ }^{\dagger}$ Financial University under the Government of the Russian Federation

${ }^{*}$ Corresponding Author, Emails: seregina.tatiana@yahoo.com; Seregina.tatiana@gmail.com

${ }^{¥}$ Moscow Aviation Institute, Russian Federation, Email: Svet_285@mail.ru

'̇Tula State University, Russian Federation, Email: godvidruzhinin@mail.ru

ÎKazan Federal University, Russian Federation, Email: guzel-shagivalee@mail.ru

(C) 2019 Seregina et al. This is an Open Access article distributed under the terms of the Creative Commons Attribution License (http://creativecommons.org/licenses/by/2.0), which permits unrestricted use, distribution, and reproduction in any medium, provided the original work is properly cited.
} 


\section{Introduction}

The pace of modern globalisation has led to a consensus of goals for the world community, and among them, the accomplishment of effective development of intercultural communicative competence remains paramount (Abisheva et al., 2019). Foreign language learning is a major paradigm and a key to the effective, high-quality formation of skills in intercultural dialogue (Al Jarrah, 2019). Education in a multicultural environment is one of the priority problems of modern Russian society. Integration processes have become an important part of the modern globalised world. In this paper the authors adhere to the definition of globalisation as a process fueled by and resulting in increasing cross- border flows of goods, services, money, people, information, and culture (Oliver, 2017). According to the convergence principle, contemporary globalisation is westernisation or Americanisation writ large, a fulfilment in instalments of the classical imperial and the modernisation theses (Pieterse, 2019; Nikolaeva et al., 2018).

Education in a multicultural environment should be based on the doctrine of spiritual and moral intercultural dialogue (Zhukova et al., 2019). The indisputable stimulus in the formation and development of communicative competence of the modern community is learning foreign languages as a key for an effective intercultural dialogue and understanding (Ter-Minasova, 2000). Language is a key paradigm of intercultural dialogue. It is indeed a social phenomenon with territorial, ethnic, historical, religious grounds, used for communication, understanding, transmission, and assimilation of information (Ter-Minasova, 2000). The integrating function of a language is dominant in intercultural communication, both in interpersonal and sociocultural contexts (Parekh, 2003). The language map of our planet is so diverse and developed in different degrees. It provides unique opportunities for various human activities (Pais and Costa,
2017). However, the most important function of a language is understanding (Crosbie, 2014). The term "intercultural communication" means an adequate understanding of the representatives of different cultures (TerMinasova, 2000). An adequate understanding is respect for ethnic, cultural, and religious values of all nations. Interracial, intercontinental, geopolitical issues shall become historical archaisms when it comes to intercultural communication.

Due to the globalisation, the concept of "a global citizen", which can be attributed to sociological neologisms, should be defined. It is about education within the universal respect in the intercultural world, a reflection of one's culture with the achievements of world civilisation. Levelling of ethnic, religious, political prejudices is the task of a general education doctrine in many European countries (Parekh, 2003). The cultural-centrist model of education is influenced by cultural globalisation and uplies the focusing of material and spiritual efforts of people on building a metasystem through social and spiritual unity (Ying, 2016).

First of all, multicultural education should be based on the ideas of multiculturalism. The traditional paradigm of education in Russia is outdated, and in 2000, it was replaced by the new state standards of education that are continually being improved. Updating of the education paradigm should be qualitative, based on the multicultural perception of coexistence with other ethnic groups, enrichment of cultures and self-identification in a multi-ethnic society. It is a priority in the modern educational system in Russia. Innovation and reform of education is the main problem in the formation of intercultural competences in society.

Thus the purpose of this research is to highlight the importance of multiculturalism and learning a second language in the Russian system of higher education. Analysis of the experiments, conducted in the large Russian universities, shows new ways to solve 
problems in intercultural education. The research is organised in the following ways: it begins with a literature review reviewing the key publications in the field. This follows a brief description of the materials and methods describing the research design, sample, tools, experiments, data analysis and ethical issues entailed in conducting the same. Finally, the results are critically discussed in the sections following this.

\section{Literature Review}

Multiculturalism has become so important that it forms a foreign policy vector of modern states. It consists of the assertion of normative principles that affirm the value of such cultural diversity in terms of equality between groups, and the realisation of these values in institutions and policies (Sarmento, 2014). Parekh (2001) argues that all multicultural societies, however, ought to embrace multicultural values and policies.

The historical circumstances have led to the need for multiculturalism in all countries, especially the United States, Canada, Australia, and the United Kingdom (Babaii, 2018). Migration processes predetermined the importance of this phenomenon in all spheres of the society, including education, as an integral part of forming a healthy society (Crosbie, 2014).

Recent studies show that the development of language teaching has been strongly influenced by institutions whose purpose is to promote an ideal of a particular national culture (Beacco \& Byram, 2003; Hassan \& Starkey, 2000). At a European level, language education policy has been explicitly developed in the context of education for democratic citizenship. This language education policy assumes that all learners can develop identities not only as national citizens but also cosmopolitan citizens (Starkey, 2007).

In turn, Banks (2015) identifies three primary goals of multicultural education:

- making any necessary adjustments to schools such that they provide a more supportive education environment;
- high-quality educational experiences for all students regardless of their ethnicities, racial groups and social classes;

- providing similar educational opportunities for both genders.

The issue of multicultural education is relevant and essential for the post-Soviet states (Abisheva et al., 2019). The disintegration of the Soviet society, its isolation and inculcation of artificial stereotypes significantly slowed down the constructive relations with the world community and the scientific and professional community (Zhukova et al., 2019). In the conditions of a multi-ethnic and multicultural community, the destructive phenomena in education are not completely eliminated (Bleszynska, 2010). Non-observance of social justice with the cultural, ethnic, linguistic and other differences has become one of the most critical problems of the world community.

For comparison, the Chinese education system in the context of "metropolis - periphery" is not significantly different from the Russian. Shanghai, Beijing and other cities are places of economic, cultural and professional concentration, as well as Moscow, St. Petersburg, Nizhny Novgorod in Russia. Accordingly, using public financial resources in these cities is predominant. The problems of Chinese peripheral education are relevant and have similar trends. The situation is approximately the same in Ukraine, Kazakhstan, and Azerbaijan (Zhukova et al., 2019).

It is worth noting that rapid economic growth motivated the Chinese to study English. Although in recent years in the context of the political "games", the issue of the suppression of Chinese by English is relevant, English is an integral part of the education system of China and Gaokao (High Educational Exam - an entrance complex test at the university). Russia and other post-Soviet states shall learn from countries with effective multicultural education (Balitskaya, 2008). 


\section{Methods}

This research experiment was conducted at Tula State University amongst different groups: one group of freshers and two groups of juniors. The freshers are always more diligent and active; they have high motivation. These arguments were important, choosing a group of first-year students. Freshers" enthusiasm was supposed to be a key criterion during the whole process and to give the best result. The juniors had to learn professional materials. The experiment involved 78 people aged 17 to 20 years. All the participants were informed about the content of experimental work. All the students under 18 years were to obtain written consent from the parents to be involved in research work. None of the students and experts (psychologists and culturologists) refused to participate in the experimental work.

The experiment using alternate classical teaching methods with innovative ones are shown in Table 1.
Table 1: Teaching Methods Applied

\begin{tabular}{|l|l|l|}
\hline Classical & $\begin{array}{l}\text { Hard- } \\
\text { learning } \\
\text { audio tests }\end{array}$ & $\begin{array}{l}\text { Reading, Translation, Listening, Answers, } \\
\text { Dialogues on the topic, Tests of different } \\
\text { levels, Essay writing }\end{array}$ \\
\hline Innovative & E-learning & $\begin{array}{l}\text { Watching the thematic films, Clips, Audio texts, } \\
\text { Video projects, and presentations }\end{array}$ \\
\hline
\end{tabular}

\section{Results}

During two months, the alternation took place: one topic was studied traditionally, the second one - through all kinds of maximum visualisation. 4 classes ( 2 classes per week) were defined for studying one topic. At the end of each topic, the students wrote a test.

The method "stop-frame" for studying vocabulary can be an example. After the students' signal, the teacher stopped watching for a few seconds to give the opportunity to write an unknown word. Then, the students were searching for the meanings of the words in the dictionary for some time. It is worth noting that no student opened the book dictionary, which was on the table. After watching the clip for the second time, the teacher made "a freeze-frame" of the unknown words, and the students repeated them, demonstrating 85 per cent of the correct answers.

The method of the contextual meaning of words can also be used following the example of excluding words from the context. Students were asked to include a specific word/phrase in another context. The task was done in a group (including 2 or 3 people), and it had to be represented in the form of a dialogue or situation. Students remembered the context of the expression or use of the word in 75 per cent of cases. This method activates conversation practice and vocabulary use. Thus the students demonstrated their general knowledge.

Modelling and role-playing are the other approaches to the assimilation of material and information. Studying the topic "Traveling" and watching films about countries and continents, the students had to act in the different situations (meeting, greeting, acquaintance, saying goodbye, correspondence) in different countries (work in pairs). Examples of the tasks: the greeting of the European and Chinese, the European says goodbye to the Muslim family, a business meeting with the Japanese and more. Conventionally, each situation was modelled on the intercultural perception and differentiation of cultural differences. It is worth noting that even with the maximum assimilation, it was difficult for students to give up their social habits in modelling situations. For example, if the Europeans are 
characterised by a wide embrace, friendly expression of joy at the meeting through a kiss, greeting "cheek to cheek" (demonstrated by students), the Muslims do not interpret it as acceptable. The teacher models a similar situation, and the students easily remember the cultural differences.

Psychologists and culturologists were also involved in the experiment. The psychologists' task was to diagnose the motivational level of the students during the experiment. At the end of each topic, the students did a test questionnaire, which made it possible to determine the level of motivation in the classical and innovative methods of teaching. The effectiveness of using innovative methods increased on average by 17 per cent. The culturologists' task was to determine the increase of knowledge of each student's cultural development. The rapid diagnostic tests were conducted before studying the topic and at the end. The effectiveness of innovative methods increased knowledge of the cultural aspect on average by 35 per cent. The experiment at the Kuban State University showed the importance of motivation, learning a foreign language in traditional conditions. The diagnosis was made by writing an essay on the topic: "What is the purpose of foreign language learning?" 158 students, aged 17 - 20, were divided into three groups: freshers - 60, second-year students - 50, graduates -48 . Then, the content analysis of student works was done. Analysing students' essays, the attention was focused on the motivational quotes of an empirical nature. Statistics of motivational phrases were divided into two parts: positive and negative statements. The units of account were the following quotes: the general development of the person, to become a sought-after expert, to watch films in the original language, the desire to travel, communicate with native speakers, go abroad, and study there. The freshmen's motivation was the highest, but it was not a realistic self-assessment. The unconscious motives are explained by euphoric emotional outburst. It is confirmed by the motivation decline of second-year students when learning difficulties have lowered the optimism of early studying. The graduates have shown reasonable motivation, its meaning, and realism.

The survey, conducted at the Moscow Aviation Institute, showed the importance of the professional component in learning a foreign language. The experiment involved 152 technical graduates $(6$ groups: 5 experimental, 1 - control). Their average age was 20-21. The following issues were motivational units of this survey: for professional use, for improvement of selfassessment, for passing exams, at the parents' request. The survey results showed a low level of motivation among the graduates (see Table 2).

\begin{tabular}{l|c|}
\hline Table 2: The Survey Results & In Per cent \\
\hline Motive (from the questionnaire) & 18 \\
\hline For Professional use & 21 \\
\hline For Improvement of self-assessment & 42 \\
\hline Only for Passing Exams & 19 \\
\hline At the Parents' Request & \\
\hline Source: Developed by the Authors
\end{tabular}

The successful experiment of the Moscow Aviation Institute showed one of the ways to increase motivation. Students of two groups (38 people) studied English on the same programme. During two months of the experiment, one group was assessed by the tests, and the second group was assessed in oral and written forms. At the end of the experiment, the diagnostics of students' knowledge of learning new material were conducted. The first group showed qualitatively better results (57 per cent), compared to the second one (43 per cent). Students noted their great interest in the 
preparation of tasks, as they knew about testing, and they prepared with more responsibility (a psychological aspect played its role).

For many years, in teaching practice, there is an "unspoken" terminology, which determines the student's abilities to perceive and learn languages: "strong" and "weak". Without paying great attention to the ethical side of the issue, professional teachers intuitively divide these two groups, setting a difficult task to activate the motivation of the "weak".

Testing, in its various forms, is the most effective method for assessing knowledge of students of all ages and nationalities, at all stages and levels of education. An example of some international tests is appropriate. The IELTS statistics is obvious. 121 countries give the possibility to take the test in $\mathbf{5 0 0}$ locations, mostly concentrated in areas with a large population. If by the end of the 90 s of $X X$ century the number of people who had passed the exam was about 80 thousand, in 2007, more than 1 million candidates did it, in 2012 2 million, in 2011 - 1.7. As for the TOEFL test, its statistics are slightly higher because it is recognised as the most popular test in the world: there are 4500 places for passing it in 165 countries. TOEFL results are accepted in 9000 educational institutions.

Taking into account the experience of the USA, the United Kingdom, Australia, and Canada in language testing, Russian scientists and teachers have the opportunity to use the actual experience of foreign schools that allows solving the problem of language testing in Russia.

Nonetheless, new approaches in the system of higher education in Russia mainly show the positive dynamics in foreign language learning. The innovations took place by the alternation of two approaches at Tula State University. As shown in the statistics (Figure 1), the positive dynamics of the results have always been more significant with the use of innovative methods.

Figure 1: The Dynamics in Foreign Language Learning Using Two Approaches

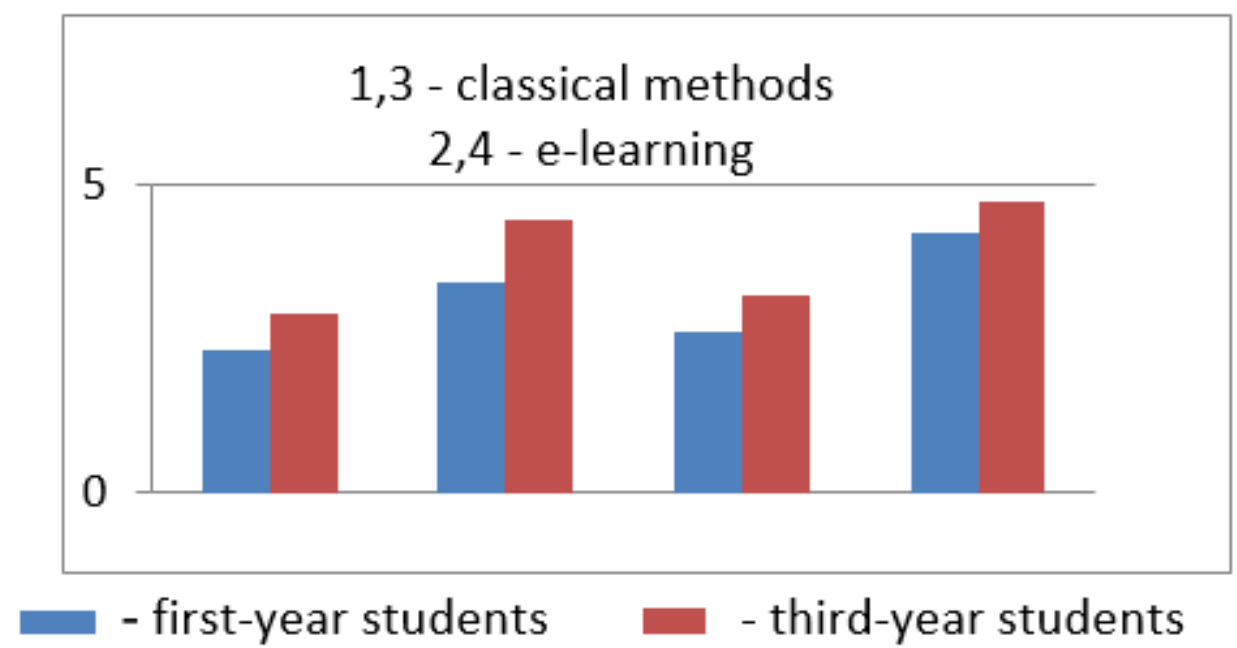

Source: Developed by the Authors

Using e-learning methods have shown the students' readiness for potential selfeducation. Thus, group's activity is evaluated at 97 per cent. In the second grade, the majority of students (even the most passive students) installed the different mobile applications for translation. In the third grade, 100 per cent of students used online translators on their smartphones (the teachers did not insist on it). According to the psychologists, the ability to use a gadget in the classroom "liberated" students on a 
subconscious level: nowadays, it is much more natural and more efficient for young people to search for the meaning of a new word in the mobile app. The results of listening and speaking are improved. The ability to listen and repeat a word via mobile applications improved the memorisation and learning by 35 per cent. Using the "freeze-frame" method, searching for the meaning of a word in the mobile application took approximately 20-30 seconds while doing the same in a book dictionary required 1 and even 2 minutes.

On the other that e-learning methods contributed to a more relaxed atmosphere; classes were held actively and effectively. The freshers became more interested in foreign language learning because a relaxed atmosphere, on a subconscious level, gave the effect of maximum impact. Prepared portfolios, presentation, test results have improved in their quality.

The juniors were learning a foreign language, using a more professional approach. Professional vocabulary, information directly related to professional activity, the opportunity to learn the experience of other countries increased their interest. The students' projects in English showed a more profound analysis of the speciality and motivation to study the subject. Two groups were deliberately chosen, as a positive result was expected.

Table 3. Analysis of the Results (in percentage)

\begin{tabular}{l|c|c}
\hline Methods & $\begin{array}{c}\text { Hard-learning } \\
\text { Freshers (in per cent) }\end{array}$ & $\begin{array}{c}\text { E-Learning } \\
\text { Juniors (in per cent) }\end{array}$ \\
\hline Reading & 37 & 56 \\
\hline Writing & 39 & 52 \\
\hline Listening & 35 & 44 \\
\hline Speaking & 32 & 42 \\
\hline Source: Developed by the Authors
\end{tabular}

Classical methods of teaching significantly decreased the activity, and consequently, the result. By the end of the experiment, teachers had to combine e-learning and hard-learning according to the reasoned students' requirements. Finally, the teachers developed the case, where both techniques are appropriately combined (see Table 3 ). This case was tested at schools of the Tula region, and received positive teachers' and students' feedback.

The results of the Kuban State University demonstrates the other ways to motivate students, factors for successful learning, and obstacles to achieve the desired results. What do you mean?

This followed the results of content analysis of students' motivation (see Table 4), conducted in two groups of students:

- Intrinsic motivation includes general development, opportunities to become a sought-after specialist, to watch films in the original language.

- Extrinsic motivation includes the desire to travel, communicate with native speakers, to go abroad.

Table 4: The Results of the Content Analysis as a Percentage

\begin{tabular}{|c|c|c|}
\hline Course & Intrinsic motivation (in percent) & Extrinsic motivation (in per cent) \\
\hline 1 & 52.2 & 47.8 \\
\hline 2 & 48.6 & 51.4 \\
\hline 5 & 67.5 & 32.5 \\
\hline
\end{tabular}

It is worth noting that the analysis of subjective arguments was the central unit. When purely subjective psychological aspects are involved, and when motivation depends on many 
personal factors, it is useless to talk about their advantages. The primary task of the teaching staff is optimisation and balance of the intrinsic and extrinsic motivation. It is necessary to optimise the educational process, effectively organise the educational environment for active development of professional competencies.
The experiment of Moscow Aviation Institute shows the importance of the motivational aspect of language education in Russia, especially among technical specialists who are in demand and competitive if they are highly qualified (see results in Table 5).

\begin{tabular}{|c|c|}
\hline 85 & They do not read special literature in a foreign language \\
\hline 22 & They use a foreign language in any situation \\
\hline 11 & They are able to read well \\
\hline 8 & They can fluently speak on household topics \\
\hline 79 & They describe their level as low \\
\hline
\end{tabular}

These statistics are rather disappointing. The low motivation among engineering students is caused by the prospect of future professional activity. It is obvious that the majority of respondents do not see prospects of using a foreign language in their future career. According to this study results, some appropriate tools to increase the motivation of technical students are proposed.

- The model of foreign language learning on an interdisciplinary basis is constructed;

- The potential of using a foreign language in the future professional activity is determined;

- The organisational and pedagogical conditions for increasing students' motivation are predetermined and implemented.

The results showed that the "weak" students, who had learned English words through the electronic vocabulary game, remembered more words than the "weak" students, who had learned the words on paper sheets. These results emphasise the importance of interactive forms of learning, individual and integrated approaches, the visualisation of the educational process. Thus, it can be stated that the experiment results are qualitatively meaningful and motivationally appropriate.
They are recommended for use and implementation in other universities and schools.

\section{Discussion}

A number scholars confirm that testing is a motive for students to learn a foreign language (Smith and Stansfield, 2017; Gass, Van Gorp \& Winke, 2019; Peng, 2019). The scientists of Michigan, Cambridge, and other universities are the reputable developers and leaders in this field. Research and testing, conducted in more than 60 years, have accumulated rich experience, included in the world of science, and are known worldwide (Charles \& Pecorari, 2015; Kang et al., 2019). Multi-million "army" of scientists, teachers, statisticians, and respondents made this a truly revolutionary process structured and optimised, taking into account all the nuances and requirements of a multicultural world community. The validity of such tests as TOFEL, IELTS, BEC, CAE, CPE, and others are widely recognised. It is worth noting that the development and certification were made, taking into account the intercultural heterogeneity of users. The development of tests is also continued in Russia (Zhukova et al., 2019). The structure and methodology of tests have been modified not only by the technological advances for many decades. One of the most fundamental aspects in the 
evolution of testing is the analysis of opinions and requirements of test users. In recent decades, millions of people have been tested and received the international certificate for teaching, work and other purposes in Englishspeaking countries.

The multicultural education in the USA, Australia, and the United Kingdom should be an example for other countries because they have passed complicated processes of ethnic, interracial transformation and got experience in overcoming the xenophobic prejudices (Balitskaya, 2008). The search for adequate models of foreign language learning is held in the conditions of preservation and unification of human values in multinational countries that are the majority ( 90 per cent). The stabilisation processes of multicultural society have developed a single strategy based on humanistic ideals in the cultural and educational vector (Spring, 2017).

Analysis of the results of Tula State University shows the high effectiveness of e-learning methods. The students' motivation has increased significantly. The positive dynamics were observed at all stages of learning: reading, writing, listening, speaking. These results are consistent with the study of Kukulska-Hulme (2009). During the experiment, the students were fully immersed in the English-speaking environment. Watching films, videos, clips provided visualisation of the studied material. Using new game techniques ("freeze-frame", an immersion in the situation, exclusion/inclusion in the context) showed how the effects can be increased.

The results of Kuban State University allow making some logical conclusions. Implementing the above-mentioned results of the experiment, increasing the students' motivation is a definite natural process. Experimental verification of the study showed the feasibility of some methods to motivate students. For example, writing a report on practice in a foreign language, doing assignments of research, the presentation of the master's work in a foreign language can motivate the students.

The bonuses also motivate students. The teachers of Moscow Aviation Institute developed a motivational checklist:

- participation in scientific conferences;

- publications in professional journals;

- recommendations of the university administration to a prospective employer;

- recommendations to enter the postgraduate studies;

- speeches at the enterprises (for practice).

On the basis of statistics, it is essential to talk about the possibility of studying abroad. The number of students who want to study abroad increases every year. Russia's international cooperation in education and intercultural communication, effective diplomatic cooperation at the highest level has provided equal opportunities for the citizens. When only students from rich families could potentially study abroad 20 years ago, now education in foreign universities became more affordable through university student exchange programmes.

However, some aspects of this issue are controversial and problematic, in particular, the problem of migration. If the number of students who want to study abroad increases, the number of students who want to return home decreases. According to official data of "Rosstat" in 2016, 313210 people left the country. In the period from 1989 to 2015, about 1.5 million people emigrated. Unofficial statistics are much higher. The opportunity to stay in another country (more developed), is caused by social, economic, and psychological factors. The undeveloped infrastructure of the provinces, the lack of employment and other problems force the young people to leave Russia. There is evidence to suggest that many countries compensate for their demographic situation at the expense of international students and welcome the youths. The situation is similar in other post-Soviet states 
and around the world. To stop an outflow of the millennials is a task of national importance.

\section{Conclusion}

The purpose of the current research was to probe the role of language in intercultural communication. The results show qualitative changes in the minds of young people in the learning process. The freshers were motivated to a greater extent. It is easily explained by the euphoria of "freshers'maximalism" when inspiration increases self-confidence. There are factors that reduce second years' motivation: the difficulty of the subject, the need for regular classes. However, there is a significant change in the consciousness of graduates and, accordingly, an increase of the intrinsic motivation due to the identification with highly qualified specialists. Using advanced technologies provides an increase in the motivation level and, consequently, the result. Stable and actual features of professional skills (the ability to extract information on the speciality from foreign sources, and use it in the industrial activities, the ability to communicate and negotiate with potential colleagues, investors within professional boundaries; ability to plan education and establish links between forward-looking, strategic, tactical and operational objectives of education) can be motivating.

Teachers are faced with the problem of lack of methodological literature that meets the new requirements at all stages of foreign language learning. The ideas of multiculturalism are very poorly presented on the pages of textbooks, and teaching manuals. Regardless of the regions, the state programme is being implemented due to the enthusiasm of teachers, rather than the supply of high-quality scientific and methodological materials. Using a foreign language in oral and written forms is a significant component of its learning and understanding. This dogmatic statement should be a priority, approving the state qualification programmes for training specialists. The training of staff who will meet the new education criteria remains another important aspect. The professional re-training of teachers should be qualitatively new. Every teacher should have the opportunity to learn the latest teaching methods. There is a lack of teachers in linguistic studies, cultural studies, specialists in intercultural communication. Training of these specialists and their work at high school will help to solve many problems, create a qualitatively new educational route of the multi-cultural outlook in multinational countries.

\section{References}

Abisheva, K., Nagimzhanova, K., Aykenova, R., Kapanova, A., Koldasbayeve, Z., \& Kanapyanova, A. (2019). Cross-cultural competence of communicators as a way to create a positive eco-informational environment. Space and Culture, India, 7(2), 76-88. https://doi.org/10.20896/saci.v7i2.460

Al Jarrah, H. Y. (2019). Six thinking hats: An analysis of the skill level of Jordanian vocational education teachers and the extent of skill application. Space and Culture, India, 7(1), 170-185. https://doi.org/10.20896/saci.v7i1.470

Babaii, E. (2018). Multiculturalism: An asset or a problem? Implications for Intercultural Education. Intercultural Communication Education, 1(2), 45-53.

Balitskaya, I.V. (2008). Multicultural education in the USA, Canada, and Australia. Thesis. Moscow.

Banks, J. A. (2015). Cultural diversity and education: Foundations, curriculum, and teaching. Routledge: London

Beacco, J. C., \& Byram, M. (2003). Guide for the development of language education policies in Europe: From linguistic diversity to plurilingual education. Council of Europe: France

Bleszynska, K. M. (2010). Intercultural education in post communist countries. Intercultural and multicultural education. Enhancing global interconnectedness, 69-83. 
Charles, M., \& Pecorari, D. (2015). Introducing English for academic purposes. Routledge: London

Crosbie, V. (2014). Capabilities for intercultural dialogue. Language and Intercultural Communication, 14(1), 91-107.

Gass, S., Van Gorp, K., \& Winke, P. (2019). Using different carrots: How incentivization affects proficiency testing outcomes. Foreign Language Annals, 52(2), 216-236, https://doi.org/10.1111/flan.12389

Hassan, X., \& Starkey, H. (2000). Civilisation. Kang, T., Arvizu, M. N. G., Chaipuapae, P., \& Lesnov, R. O. (2019). Reviews of academic english listening tests for non-native speakers. International Journal of Listening, 33(1), 1-38, https://doi.org/10.1080/10904018.2016.1185 210

Kukulska-Hulme, A. (2009). Will mobile learning change language learning?. ReCALL, 21(2), 157-165, DOI: https://doi.org/10.1017/S0958344009000202

Nikolaeva, Y. V., Grimalskaya, S. A., Petrosyants, D. V., Zulfugarzade, T. E., Maystrovich, E. V., \& Shestak, V. A. (2018). Philosophical view of multiculturalism in modern European cinematography. European Journal of Science and Theology, 14(6), 205214.

Oliver, P. (2017). The concepts of globalisation and culture. In Globalisation, education and culture shock (pp. 10-20). Routledge: London

Pais, A., Costa, M. (2017). An ideology critique of global citizenship education. Critical Studies in Education, 3, 1-16.

Parekh, B. (2001). Rethinking multiculturalism: Cultural diversity and political theory. Ethnicities, 1(1), 109-115.

Parekh, B. (2003). Cosmopolitanism and global citizenship. Review of International Studies, 29(1), 3-17.

Peng, M. Y. P. (2019). Testing the mediating role of student learning outcomes in the relationship among students' social capital, international mindsets, and employability. The Asia-Pacific Education Researcher, 28(3), 229-237.

Pieterse, J. N. (2019). Globalization and culture: Global mélange. Rowman \& Littlefield Publishers: New York

Piller, I. (2017). Intercultural communication: A critical introduction. Edinburgh University Press: Edinburgh

Sarmento, C. (2014). Interculturalism, multiculturalism, and intercultural studies: Questioning definitions and repositioning strategies.

Smith, M., \& Stansfield, C. W. (2017). Testing Aptitude for Second Language Learning. Language Testing and Assessment, 1-14.

Spencer-Rodgers, J., \& McGovern, T. (2002). Attitudes toward the culturally different: The role of intercultural communication barriers, affective responses, consensual stereotypes, and perceived threat. International Journal of Intercultural Relations, 26(6), 609-631.

Spring, J. (2017). The intersection of cultures: Multicultural education in the United States and the global economy. Routledge: London

Starkey, H. (2007). Language education, identities and citizenship: Developing cosmopolitan perspectives. Language and Intercultural Communication, 7(1), 56-71.

Ter-Minasova, S. G. (2000). Language and intercultural communication. Moscow: Slovo, 634.

Ying, W. (2016). Review of the Confucius Institutes' strategy for the dissemination of Chinese culture. Chinese Education \& Society, 49(6), 391-401.

Zhukova, T., Bogoslovskiy, V., Dobudko, T., Sevenyuk, S., \& Vershinina, L. (2019). Multicultural Teaching in Regions (Within Sustainability Conception in Education). Space and Culture, India, 7(1), 274-284. https://doi.org/10.20896/saci.v7i1.437 